\title{
Biomimética no Design e Locomoção de Robô Modular Apodal
}

\section{Biomimetics in Design and locomotion of an Apodal Modular Robot}

SENOO, Guilherme Hirata; Graduando; Universidade de Brasília

guilherme.senoo@gmail.com

GOMES, Vitor Hugo Prado; Graduando; Universidade de Brasília

vitorhpgomes@gmail.com

BORGES, João Vitor Quintiliano Silvério; Mestrando; Universidade de Brasília

jquintiliano@gmail.com

VIANA, Dianne Magalhães; DSc; Universidade de Brasília

diannemv@unb.br

KOIKE, Carla Maria Chagas e Cavalcante; DSc; Universidade de Brasília

ckoike@unb.br

\section{Resumo}

A biomimética é uma área de estudo científico que requer a compreensão das estruturas biológicas e suas funções propiciando a criação de dispositivos artificiais com um design que favoreça um melhor desempenho. Este artigo aborda a concepção de um robô modular apodal bioinspirado visando apoiar inspeções em locais acidentados ou de difícil acesso humano. Em situações de desmoronamento, pode ser uma ferramenta essencial para resgate de pessoas e animais. O objetivo do presente trabalho é explorar conhecimentos acerca da locomoção de ofídios e utilizar o ponto de vista do Design para criar um módulo apropriado para a estrutura e movimentação de um robô modular, levando em consideração também as interações com as demais áreas que interferem no processo de desenvolvimento.

Palavras Chave: modular; robô; biomimética; locomoção apodal; robô modular.

\begin{abstract}
Biomimetics is a field of the scientific study that requires the comprehension of biological structures and its functions providing the creation of artificial devices with a design that favours a better performance. This article introduce the conception of an apodal bioinspired modular robot to support inspections in hilly or difficult-to-reach places. In crumbling situations, it might be an essential tool for the rescue of people and animals. The aim of this present article is to explore knowledge around the locomotion of structures and movement of a modular robot, taking into account also the interactions with other areas the may interfere in the process of development.
\end{abstract}

Keywords: modular; robot; biomimetics. 


\section{Introdução}

Acerca do conceito de biomimética, ela representa mais do que a adoção desmedida de elementos naturais, como destaca Forcellini (2002, p.64), O conceito de Biônica ou Biomimética consiste em analisar sistemas naturais e reproduzir seus princípios de solução, buscando contribuições relevantes no processo de desenvolvimento de produto. Essas adaptações permitem a criação de formas análogas, funções análogas ou ainda comportamentos análogos. De maneira que é essencial compreender a natureza, seus sistemas e imitar seus comportamentos e funcionalidades, obtendo os melhores resultados com o mínimo de impacto possível.

Trazer a natureza para o centro da discussão já foi feito por Papanek (1984) há décadas, que considerava o desenvolvimento de produtos em termos de responsabilidade ecológica e preocupação com meio ambiente. Entretanto, a biomimética vai além da preocupação ambiental oriunda das ações humanas. A natureza é uma fonte indiscutível de inspiração, e as soluções encontradas no longo período de evolução mostram que ela é excelente em reduzir custos, evitar desperdícios e reutilizar recursos (BENYUS, 2007). Benyus sugere que a natureza seja cada vez mais estudada e imitada para que nossos produtos realizem tarefas de forma mais eficiente e sustentável. O presente trabalho possui um escopo bem definido: locomoção de robôs modulares apodais, que se locomovem por entre destroços, espaços pequenos e irregulares, para inspeção em instalações de difícil acesso ou busca de vítimas em escombros.

Observa-se um número crescente de trabalhos e projetos de robôs apodais inspirados em serpentes, nas últimas décadas; Parker (1977), Hirose (1993) e Mattinson (2002). Infere-se que esse fato se deve a facilidade dos ofídios se deslocarem em vários tipos de terreno. No entanto, Dowling justifica que:

“A motivação geral pelo movimento das serpentes se deve aos ambientes onde máquinas tradicionais são impedidas devido ao tamanho ou forma e onde apetrechos como rodas ou pernas causam aprisionamento ou falha" (DOWLING, 1997 p.6).

O estudo acerca das serpentes, de sua anatomia e o modo como realiza seus movimentos pode orientar um design mais funcional e o desenvolvimento de projeto mais eficiente em termos de desempenho da locomoção desses robôs. Por outro lado, reproduzir fielmente a locomoção das serpentes em robôs apresenta vários obstáculos, principalmente técnicos, como por exemplo mimetizar os movimentos da musculatura do animal.

Nesse sentido, o objetivo deste trabalho é realizar estudos acerca da locomoção de ofídios e, por meio de uma intervenção do design, criar um módulo para a estrutura e movimentação de um robô modular, levando em consideração também as interações com as demais áreas que interferem no processo de projeto.

A opção por robôs modulares, constituídos por módulos que consistem de unidades autônomas e que conectadas em série podem desempenhar uma locomoção apodal, justifica-se pela facilidade de reposição dos módulos e de alteração de sua configuração apenas com a mudança de posição e orientação dos módulos.

O estudo da robótica modular não é algo novo, visto que desde a década de 80 (CEBOT, Fukuda Tsukuba - 1988) artigos e estudos são publicados a respeito de módulos utilizados na 
construção de sistemas robóticos.

Desse modo, com a finalidade de construir um robô capaz de movimentar-se em ambientes de difícil acesso, foram realizados estudos sobre a locomoção e anatomia das serpentes que corroboraram a característica de modularidade para o projeto. Adicionalmente, características de homogeneidade para os módulos, com a concepção de módulos iguais, é uma solução mais simples e de baixo custo.

\section{Metodologia}

Uma vez definidos os requisitos do projeto, são seguidas etapas de uma abordagem para solucioná-lo. A primeira etapa baseia-se na pesquisa em vista de elaborar um referencial teórica, tanto no campo da biologia quanto no da engenharia para entender o funcionamento de um projeto de um robô bioinspirado. A segunda etapa consiste na análise das referências adquiridas, e estudo de todos os fatores que se mostrem importantes para o trabalho do grupo EREKO, partindo-se então para a terceira etapa, que é de fato a geração de alternativas. Definida a geometria, em uma quarta etapa avalia-se o seu desempenho por meio de simulação computacional tendo em vista a reprodução de alguns movimentos básicos dos ofídios.

Nesse ponto, é possível criar rapidamente protótipos para diversos testes, que vão desde o posicionamento dos componentes internos, até alguns testes preliminares de atrito e movimentação.

O desenvolvimento de um robô modular apodal, se tratando de um trabalho interdisciplinar, envolve pesquisadores de várias áreas, engenharia mecânica, mecatrônica, elétrica, computação, uma vez que é constituído de vários sistemas: Sistema elétricos/ eletrônicos (de alimentação, de comunicação, de controle); sistema mecânico (módulos e conexões). Nesse sentido, questões relacionadas a esses sistemas podem gerar novos requisitos para a geometria final e, por conseguinte para o projeto como um todo.

Antes de tudo isso, para uma melhor compreensão acerca dos fatores que influenciam a locomoção dos robôs apodais é realizada uma revisão teórica sobre a locomoção de serpentes e robôs bioinspirados.

\section{Serpentes Biológicas e Fatores que influenciam a locomoção}

Serpentes são animais capazes de se mover eficientemente pelos mais diversos ambientes. Essa característica ocasionou um número crescente de estudos nas últimas décadas, como por exemplo, Parker (1977), Hirose (1993) e Mattinson (2002) e, ao realizar uma breve análise de sua anatomia, torna-se evidente porque suas formas de locomoção têm sido profundamente estudadas. Serpentes são animais majoritariamente terrestres, apodais (sem pernas ou braços) e ainda assim são capazes de se movimentar nos mais variados terrenos e até subir em árvores. Essa capacidade de adaptar seu modo de locomoção a diferentes ambientes levanta interesse por parte do estudo da biomimética.

Os movimentos mais comumente estudados são: concertina, serpentina, sidewinding e caterpillar, mostrados respectivamente na Figura 1. Concertina é um tipo de movimento onde a parte frontal da serpente se curva e endireita-se alternadamente, puxando a parte traseira. Já o 
movimento serpentina é o mais comum entre as serpentes, onde seu corpo deforma-se em ondulações empurrando-o para frente. O movimento sidewinding, comum em cobras que se movimentam em superfícies lisas ou escorregadias, é semelhante ao serpentina com uma diferença primordial, alguns pontos do corpo da serpente são colocados em atrito estático com o terreno para servirem de suporte, ao invés de deslizar como ocorre no serpentina. Por último, o movimento caterpillar, semelhante ao serpentina, entretanto o eixo em que o corpo do animal curva-se é perpendicular ao chão (JAYNE; BRUCE, 1988).

Tais movimentos são consequência, principalmente, do grande número de vértebras na coluna vertebral das serpentes, representadas na Figura 2a. Também contribuem para os movimentos a existência de juntas esféricas, conforme descrito por Mattinson C. (2002), que são protuberâncias que formam as junções das vértebras. Essas juntas permitem rotações em torno de três eixos de referência e facilitam os movimentos em diferentes direções já que não há um encaixe fixo, conforme consta na Figura $2 b$.

Figura 1: Tipos de movimentação das serpentes

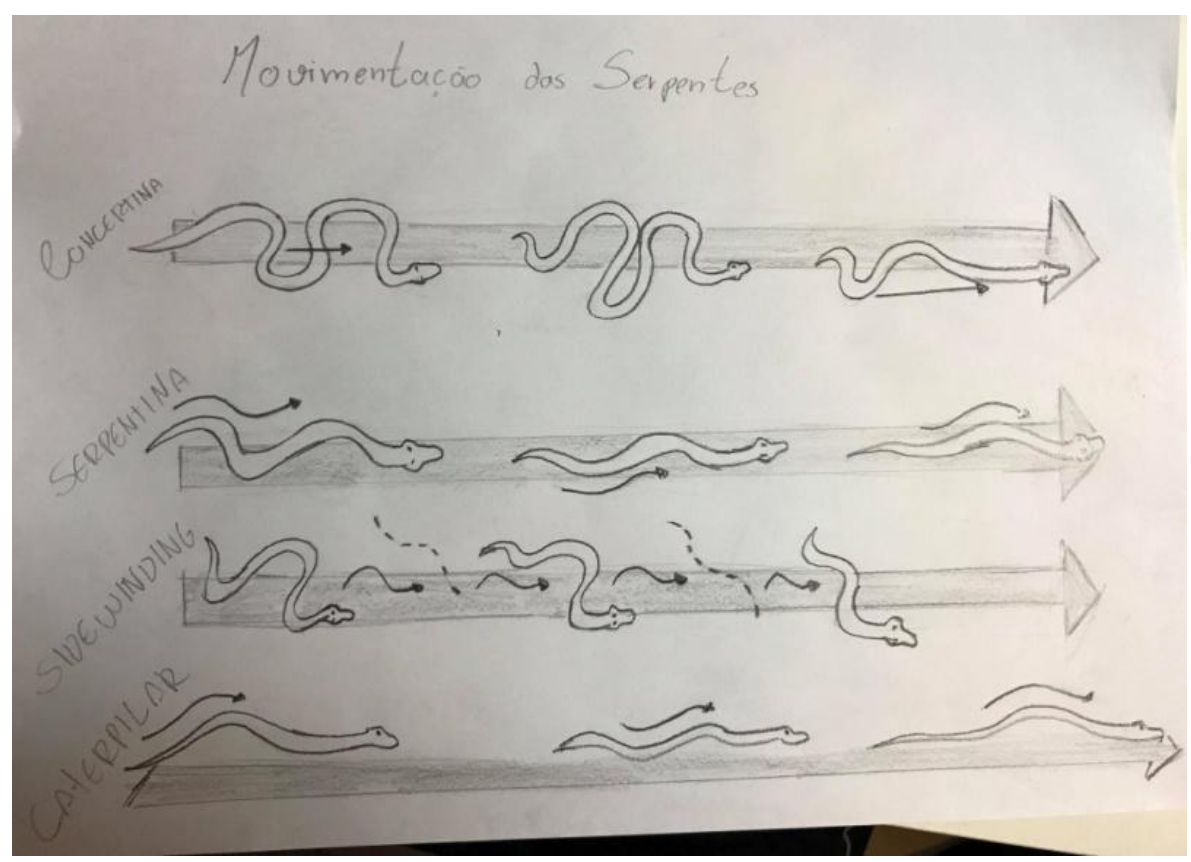

Fonte: Grupo Ereko 
Figura 2: Estudo de vértebras das cobras

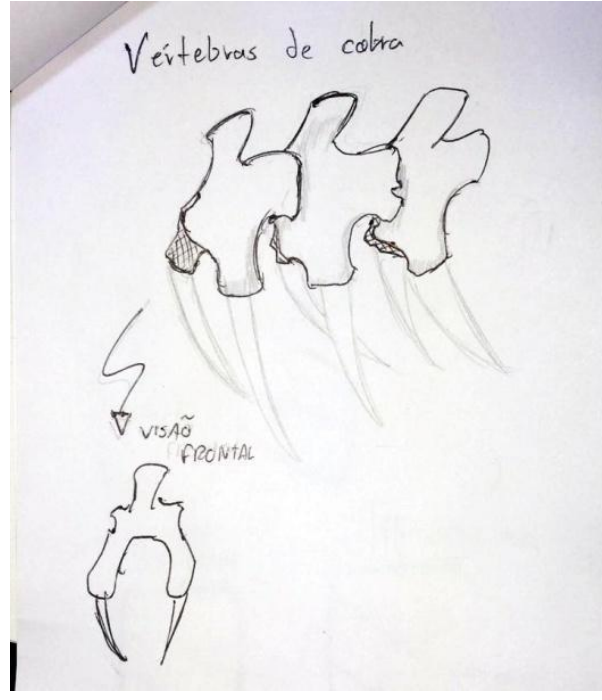

(a)

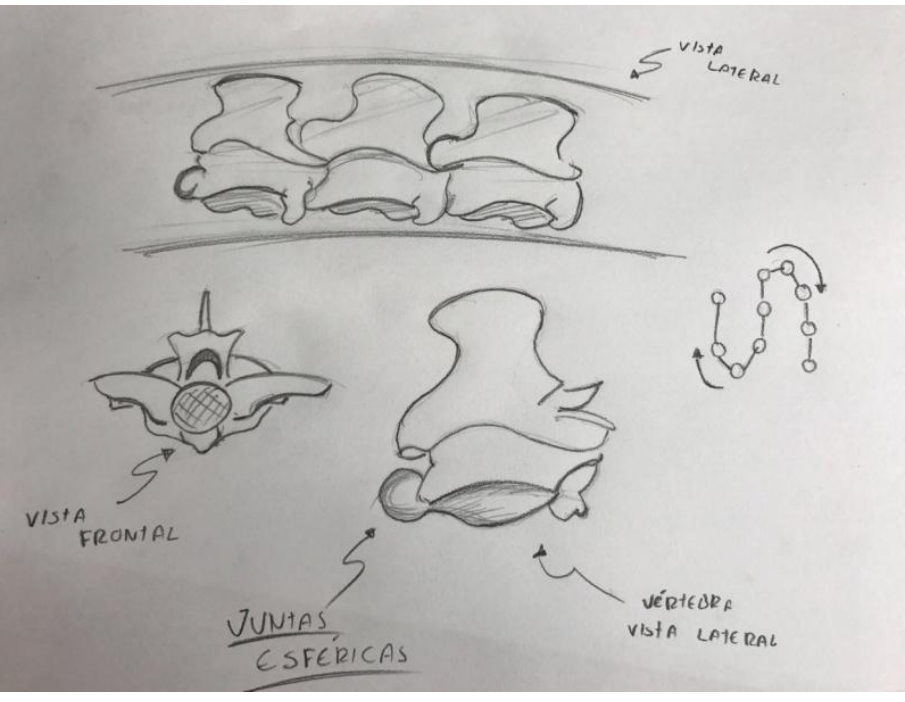

(b)

Fonte: Grupo Ereko, adaptado de [SNEEL - gabriella Levine]

Esse grande número de vértebras garante múltiplos graus de liberdade (GDL) e até mesmo uma pequena rotação do seu corpo, permitindo que executem diferentes movimentos e curvaturas, e adaptem sua movimentação de acordo com o terreno em que se encontram (PARKER, 1977; MATTINSON, 2002).

Além disso, seus corpos longilíneos e a ausência de membros garantem uma seção transversal pequena que facilita a locomoção através de espaços pequenos, como por exemplo, troncos ocos ou tubos.

A pele das serpentes é revestida de escamas sendo que cada região do corpo possui um padrão diferente. Hu, D. (2009) nos informa que as escamas são responsáveis pela proteção do corpo, auxílio na locomoção e controle na umidade retida em seu exterior. As áreas de pele entre escamas permite a serpente flexionar seu corpo mantendo uma cobertura integral de escamas para proteção. Percebe-se que cada parte do corpo das serpentes é revestida com escamas de formatos diferentes, com finalidades diferentes, seja proteção ou auxílio na movimentação. (JAYME, 2016).

O padrão e textura das escamas também proporcionam diferentes coeficientes de atrito em diferentes direções do corpo da serpente, efeito esse chamado atrito anisotrópico. $O$ atrito anisotrópico permite que a serpente deslize com maior facilidade para frente do que para trás ou para os lados, o que torna o corpo do animal mais preparado para movimentar-se em ambientes irregulares e com declives.

No rol de vantagens do padrão de movimentação das serpentes ainda pode-se citar a proximidade do corpo ao solo, que proporciona um centro de massa mais baixo, e, portanto, maior estabilidade. Em termos de locomoção, essas características permitem que as serpentes passem por áreas enlameadas, terrenos irregulares, até mesmo escalar e nadar - o que constitui 
uma grande vantagem sobre outras formas de locomoção, seja por pés ou rodas (DOWLING, 1997 p.7).

Todas essas características são fatores de interesse quando se almeja um melhor desempenho na locomoção de um robô apodal. Dowling lista uma série de vantagens de robôs inspirados em serpentes em relação às outras formas, que vão desde a estabilidade, por possuir baixo centro de massa, até o fato de que por ser formada por módulos iguais, a perda ou mal funcionamento de algum módulo não acarretará na perda total do robô, apenas afetará a sua mobilidade geral.

\section{Robôs Bioinspirados}

Em robótica, as pesquisas sobre robôs inspirados em serpentes começaram em 1972 quando Hirose construiu o primeiro robô-serpente usando um mecanismo de cordas ativas, que funcionava de maneira similar à descrição mecânica do movimento de serpentina em cobras reais (GRAY, 1946).

Após o pioneirismo de Hirose nos anos 70 e com o estudo do seu robô "Active Code Mechanism III" (HIROSE, 1993), muitos outros pesquisadores também passaram a desenvolver estudos e projetos na área (DOWLING, 2011; FORCELLINI, 2002; GOMEZ GONZÁLEZ, 2008). Convém citar alguns exemplos, como os robôs do Dr Miller; os robôs da Carnegie Mellon University, o robô de Zhang e Guo, o robô cobra do laboratório de mecatrônica do IIT de Hyderabad, o robô Anna Konda da Robotnor, entre muitos outros.

Acerca de uma metodologia para desenvolver conceitualmente um robô bioinspirado em projetos de robótica, Eroğlu (2011) sugere definir o problema sob um ponto de vista da engenharia, em seguida procurar por sistemas alternativos sob uma perspectiva biológica, e só então retornar à engenharia e gerar alternativas. Este processo incorpora bem o conceito de biomimética ao utilizar os sistemas naturais como inspiração, de modo a mudar a compreensão do problema ao influenciar diretamente nos resultados da geração de alternativas.

Para o desenvolvimento do conceito do robô, a definição de sua locomoção é de fundamental importância. A escolha de atuadores determinará aspectos essenciais de estrutura, bem como os componentes mecânicos, componentes eletrônicos e muitas outras partes funcionais.

González resume em três passos o desenvolvimento de um robô móvel: (1) O estudo do ambiente no qual o robô irá atuar; (2) A seleção dos efetores; (3) A implementação da marcha (GOMEZ, 2008, p. 14). De maneira que cada etapa é necessária para alcançar maior versatilidade, bem como maior número de formas de movimentação.

Em especial, os robôs apodais oferecem vantagem em relação aos robôs que apresentam pés, rodas ou esteiras (SAITO et al., 2011; TRANSETH et al., 2009; e DOWLING, 1997) pois ao compará-los com seus análogos naturais, percebe-se que a aplicação da locomoção bioinspirada torna possível que o robô se locomova por terrenos acidentados e com pouco atrito, além de auxiliar na estabilidade do robô, visto que a área de contato de um robô apodal é proporcionalmente maior do que um robô com pés. Além disso, a aplicação de modularidade no 
projeto de um robô garante robustez perante falhas mecânicas (ZHANG, S.; GUO, Y. , 2009; YIM et al., 2007).

De maneira geral, o campo de robótica modular que lida com robôs serpente ainda tem muitos desafios a serem superados, de tal forma que ainda haverão muitos outros modelos desenvolvidos no futuro.

\section{Geração de Alternativas}

O nome "EREKO" possui origem indígena (língua guarani) e significa "andar junto". Esse nome designa um grupo de pesquisa formado por professores e estudantes de diversas engenharias e de design, que desde 2009 atua em robótica modular, tendo como principal motivação o desenvolvimento de robôs para busca e resgate em escombros. O nome do grupo caracteriza o fato dos módulos, mesmo se tratando de unidades autônomas, somente desempenharem funções quando "andam juntos", ou seja, se estiverem conectados.

Os protótipos iniciais possuíam uma estrutura para o módulo constituída por uma carcaça de chapa dobrada, colada ou aparafusada, de metal, madeira, acrílico ou PVC, e uma haste móvel ligada ao servomotor. $O$ espaço interior era suficiente para embarcar os componentes eletrônicos, de alimentação, atuação, controle e sensores. Quando conectados em série, assumiam uma forma de cobra, no entanto por terem somente um grau de liberdade em cada módulo a única possibilidade de movimento era a "caterpillar" ( ondulação vertical ou "pitch-pitch"). As Figuras 3 e 4 apresentam protótipos dois protótipos dos modelos iniciais.

De modo a ampliar os movimentos e obter um melhor desempenho na locomoção, buscou-se, por meio da biomimética, aprofundar conhecimentos acerca da locomoção de serpentes e cobras para engendrar possibilidades de concepção de um novo modelo de módulo. Assim, com base nas referências obtidas e do estudo de projetos já existentes, partiu-se para a geração de alternativas.

Figura 3: Módulos ErekoBot $\beta-5$ (a) conectados em série. (b) detalhe do módulo
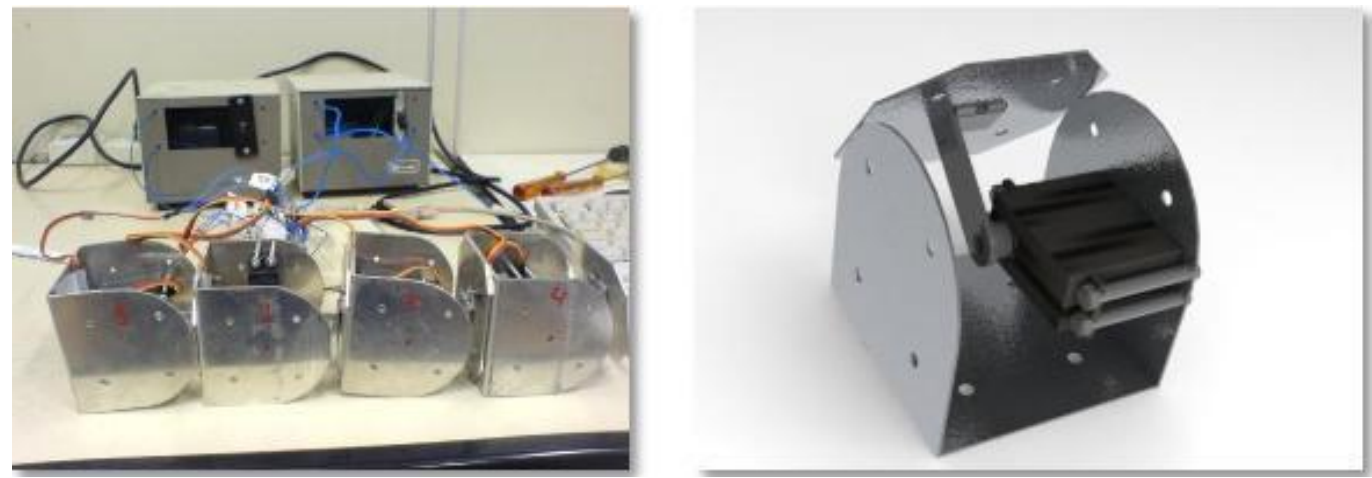

Fonte: Grupo Ereko 
Figura 4: Sigma Lily (a) Detalhe do módulo. (b) Simulação no V-REP (c) Robô construído
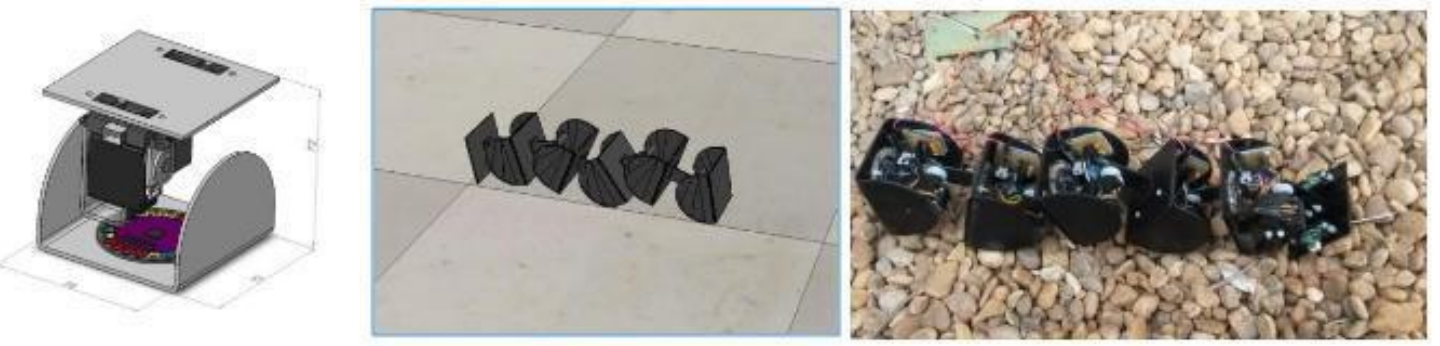

Fonte: Grupo Ereko

Uma primeira abordagem foi inspirada na forma em que as vértebras das serpentes se encaixam umas nas outras, utilizando músculos pneumáticos ou mesmo um mecanismo de cordas ativas como Hirose. Além do corpo achatado, a estrutura poderia contar com uma superfície texturizada, para simular o atrito anisotrópico das escamas.

A Figura 5 mostra o sketch de um módulo inspirado na protuberância de formato esférico de uma vértebra de serpente, conforme apresentado na Figura 2. Tal módulo foi descartado devido à dificuldade de conectar o encaixe esférico com o eixo do motor sem haver obstrução dos movimentos.

Frequentemente, ao apresentar propostas para uma equipe interdisciplinar que já desenvolveu alternativas anteriormente, uma série de limitações tecnológicas, de materiais ou construtivas associadas aos modelos a serem implementados vêm a tona. Apesar de ser a estrutura conceitualmente mais próxima da vértebra das serpentes, a junta esférica não satisfaria os requisitos atuais do projeto. O número resultante de GDL seria tão grande que sua manipulação não seria viável, seja pelos cálculos das equações de movimento, seja pelas limitações de acionamento por motores. Assim, torna-se necessário explorar outras maneiras.

Figura 5: Sketch de estudos para o novo módulo

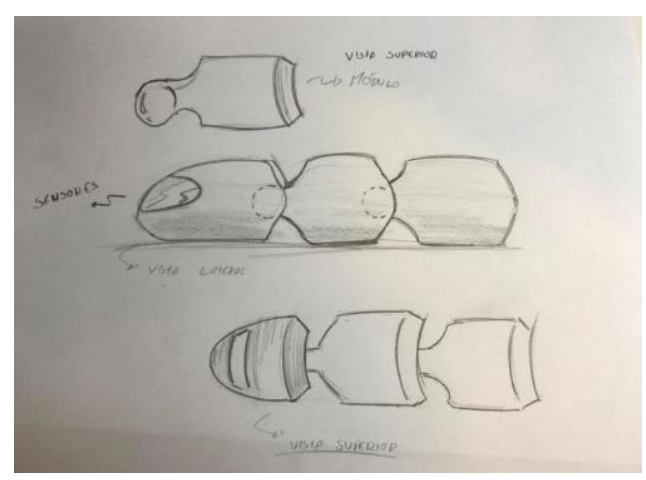

Fonte: Grupo Ereko 
Figura 6: Sketch de estudos para o novo módulo

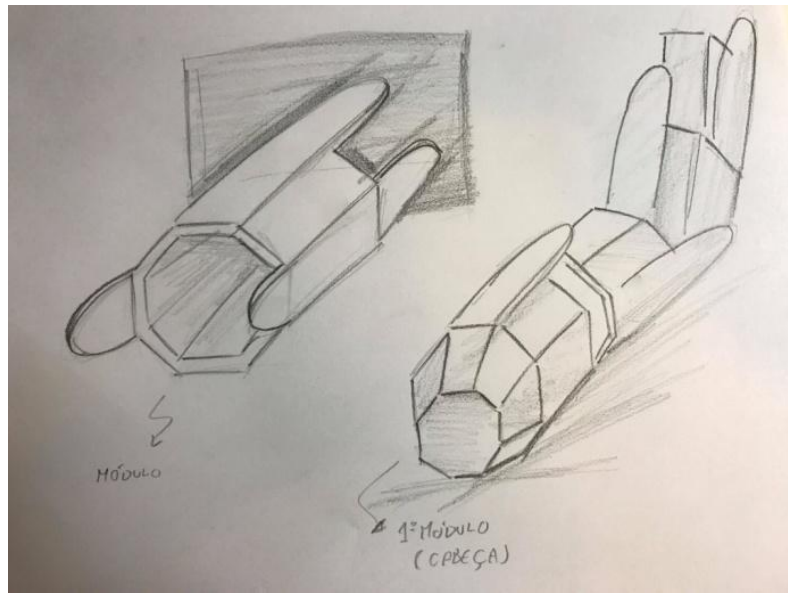

Fonte: Grupo Ereko

Figura 7: Sketch de estudos para novo módulo (Neke)

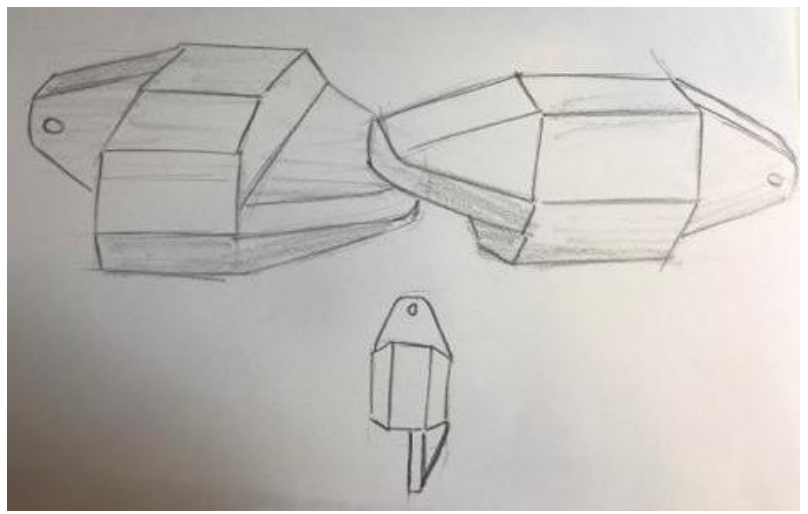

Fonte: Grupo Ereko

Várias propostas diferentes surgiram, conforme constam as figuras 6 e 7, e as limitações relacionadas à implementação dos modelos foram verificadas e testadas, tanto por meio de modelos matemáticos quanto de simulação computacional, auxiliando na escolha do módulo que melhor atendesse os requisitos de movimentação e que fosse mais próximo ao movimento das cobras estudadas.

O módulo proposto na Figura 7 possui perfil hexagonal, mais próximo do cilíndrico, mantendo a estabilidade devido à base achatada e reduzindo riscos de tombamento ou rolagem, porém ele possui apenas um GDL em cada uma de suas extremidades, limitando a sua movimentação lateral. 
Figura 8: a) Modelo 3D em Solid Works do módulo Arbok [com braço]; b) Sketches do módulo Arbok

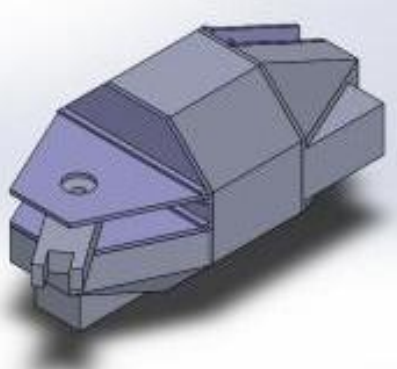

a)

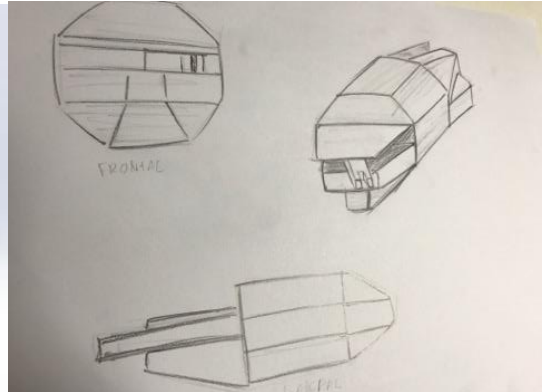

b)

Fonte: Grupo Ereko

Nota-se que o módulo da figura 8, diferente do Neke (Figura 7), possui um braço adicionado a uma das extremidades. Desta forma, uma alternativa viável foi a de adicionar um GDL para cada junta por meio de uma barra de conexão. Esta ligaria duas juntas (por exemplo), em que uma teria liberdade de girar no plano, enquanto a outra teria liberdade no plano $\theta y z$. Consequentemente o robô teria dois GDL liberdade. Nota-se que, devido a este fato, foi possível reduzir significativamente o número de módulos do projeto e até melhorar o desempenho em relação a outros modelos.

\section{Simulação}

Para melhor estudar as possíveis variáveis e aspectos do robô, antes de projetá-lo propriamente, foi conduzida uma série de simulações no software "V-REP" com o intuito de reduzir fatores que por ventura se mostrassem impeditivos para o correto funcionamento do módulo. A seguir, é realizada uma explicação sobre os movimentos realizados pelo módulo proposto no ambiente de simulação. A Figura 9 apresenta o esquema dos eixos de movimento.

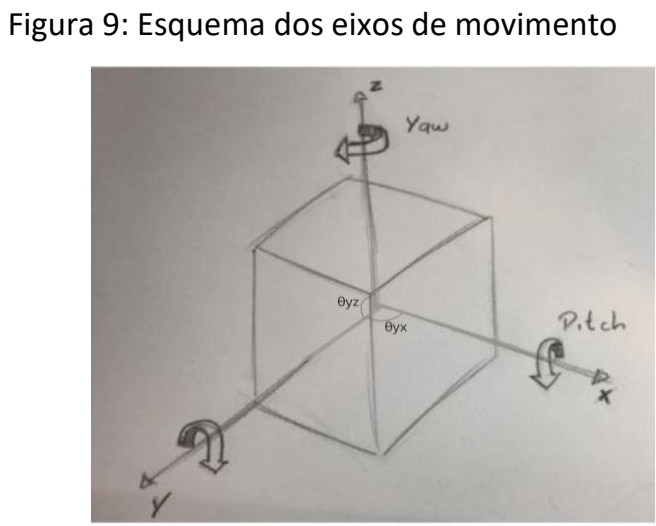

Fonte: Grupo Ereko

\section{Movimento Pitch-Pitch}

O movimento pitch-pitch é caracterizado pela movimentação do robô de cima para baixo, 
caterpilar como apresentado a Figura 1, perpendicular ao eixo x, conforme ilustrado a Figura 10. A simulação mostrou que o movimento pitch-pitch é estável e o robô se locomove para frente.

Figura 10: Simulação no V-REP do robô com o módulo proposto, movimento pitch-pitch

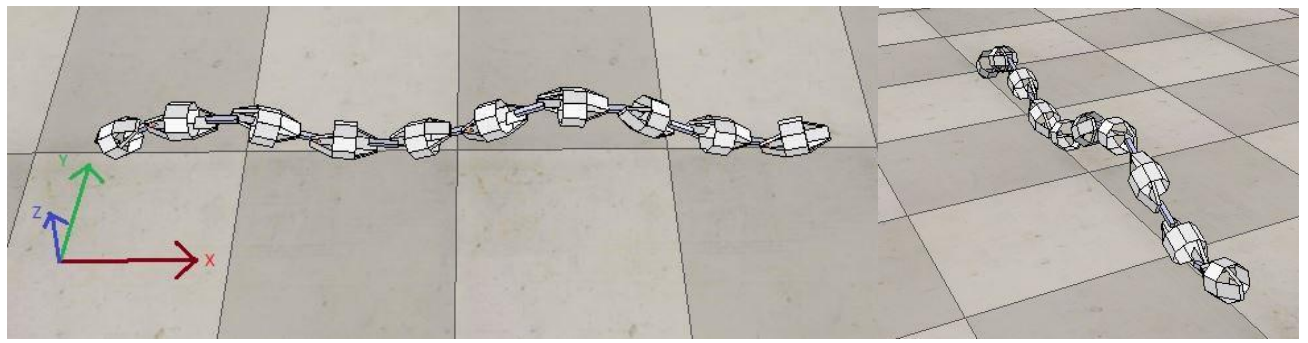

Fonte: Grupo Ereko

\section{Movimento Yaw-Yaw}

O movimento yaw-yaw se dá pela movimentação do robô para os lados, ou seja, perpendicular ao eixo $z$, de acordo com o movimento serpentina na Figura 1.

A simulação mostrou que o movimento yaw-yaw é estável, mas o robô não se locomove para frente. Para o robô se locomover a frente com esse movimento, é necessário que o atrito nas laterais do robô seja maior que o atrito para frente.

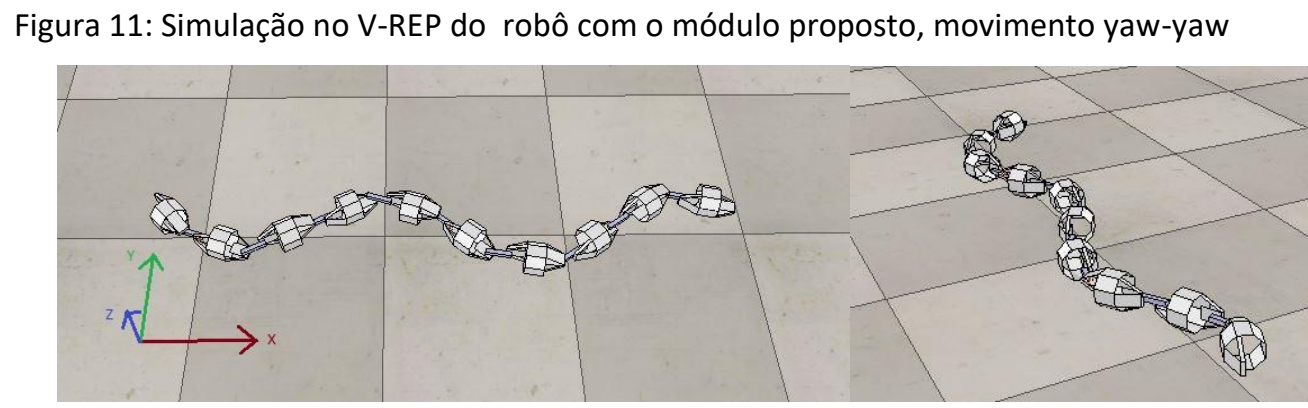

Fonte: Grupo Ereko

\section{Movimento Pitch-Yaw}

O movimento pitch-yaw, é a junção dos dois movimentos explicados anteriormente, que propicia uma movimentação composta do robô, tanto no eixo $x$ quanto no $z$, facilitando a movimentação em direções variadas.

A simulação demonstrada na Figura 12 mostra que o movimento pitch-yaw é instável para grandes amplitudes do movimento pitch. Para pequenas amplitudes no movimento pitch o robô se comporta de uma maneira não desejável. É necessário um ajuste nas equações e possivelmente no atrito para obter o deslocamento desejado. 
Figura 12: Simulação no V-REP do robô com o módulo proposto, movimento pitch-yaw

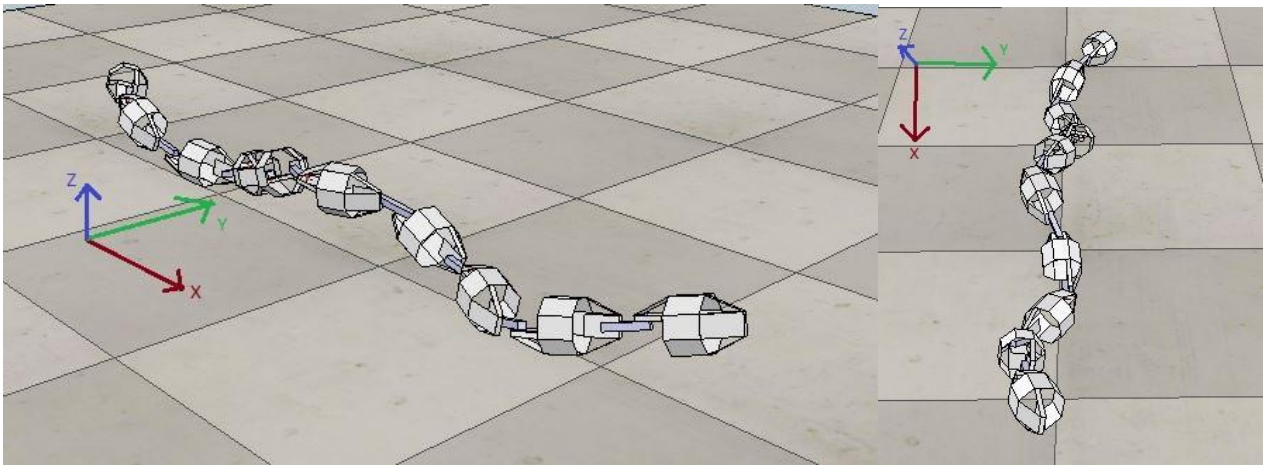

Fonte: Grupo Ereko

\section{Aspectos para o desenvolvimento do protótipo}

Alguns fatores influenciaram diretamente no desenvolvimento, como por exemplo, o processo de fabricação que será utilizado. Atualmente, os testes de geometria são realizados em uma impressora 3D, de modo que as peças e o desenho são otimizados para esse tipo de prototipagem.

Outro fator que influencia diretamente nessa questão é a especificação de todos os componentes que irão ser embarcados no módulo. Dimensões, peso, passagem de fios e dissipadores de calor, quando necessários, influenciam o projeto gerando requisitos essenciais. Destes, os principais são as dimensões e peso, pois são necessários para o cálculo de estimativa do torque necessário do motor, bem como a estimativa do tamanho e peso do próprio módulo. Nesse aspecto, fica ainda mais evidente a necessidade das interações interdisciplinares supracitadas. Com a proposta de módulo atual, é necessário ainda concretizar o módulo (por impressão 3D) e realizar diversos testes para validar esta geometria como solução.

\section{Prototipagem 3D}

Os componentes internos são responsáveis por manter o robô em plena função. Atualmente, a eletrônica embarcada é composta por servomotores "TowerPro MG995" para a movimentação, "Arduino Mini" como microcontrolador, alimentação por bateria 16340, sensores inerciais "IMU Digital Combo Board - ITG3200/ADXL345", sensores infravermelho "Sharp GP2YOA41SKOF" de curta distância para deteç̧ão de obstáculos e" Xbee 1mW Trace Antenna" para comunicação sem fio. O sistema deve ser alimentado por uma fonte que recebe $3.3 \mathrm{~V}$ e fornece 5 volts para cada componente que o módulo possui.

Os arquivos e protótipos do novo módulo possuem dimensões de 150x80x80mm por módulo e foram totalmente modelados no software Solid Works. Os modelos tridimensionais foram utilizados também no software V-Rep, para simulações de atrito e locomoção do robô antes da impressão propriamente dita.

Pode-se dividir o projeto Arbok em: Desenvolvimento do modelo tridimensional, 
preparação da peça para impressão, fabricação e montagem, como mostrado na figura 13. Para fabricação do protótipo, utilizou-se da técnica de impressão 3D em uma máquina do tipo Fused Deposition Modeling (FDM) da marca XYZ Printing modelo Da vinci Pro. O insumo escolhido para fabricação foi o filamento de ABS Branco da marca 3D Fila.

Figura 13: Prototipagem do Módulo (sem braço)

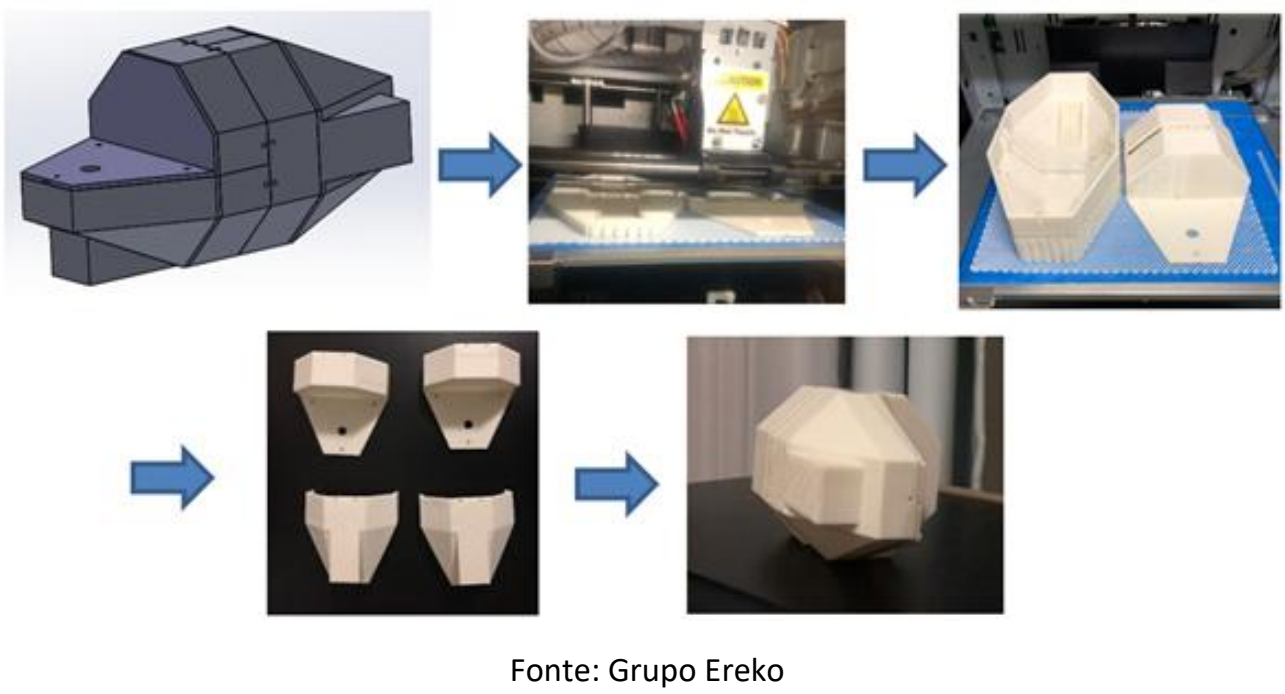

A fim de facilitar a fabricação e diminuir o tempo gasto, dividiu-se a peça em 4 partes (Figura 14). Como parâmetros de impressão utilizou-se uma temperatura de extrusão de $240^{\circ} \mathrm{C}$, mesa aquecida à $90^{\circ} \mathrm{C}$ e camadas de $0,2 \mathrm{~mm}$ de altura. Optou-se por uma peça sólida, com $100 \%$ de preenchimento para garantir a resistência mecânica necessária. Para montagem do módulo utilizou-se parafusos. A fabricação durou 14 horas e não houve a necessidade de acabamento para melhoria superficial da peça.

Figura 14: Prototipagem do Módulo (sem braço)

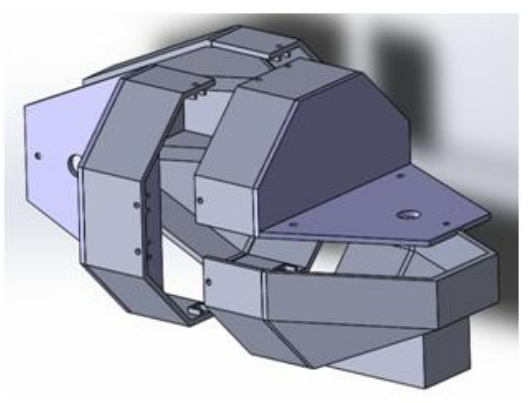

Fonte: Grupo Ereko 


\section{Conclusões}

O novo módulo é o quinto projetado pelo grupo EREKO, e nele é possível perceber melhorias notáveis em relação aos módulos passados. Há uma clara diferença em seu formato, projetado para aumentar a gama de movimentos possíveis do robô, diferente dos módulos passados onde havia apenas movimento vertical (pitch-pitch). O módulo novo possui dois graus de liberdade, por meio da barra de conexão, que possibilita sua movimentação vertical e horizontal, aumentando a gama de movimentos combinados possíveis.

Entretanto, foi observado que durante as simulações feitas no V-REP, alguns problemas surgiram em relação à estabilidade do robô para o movimento pitch-yaw, conforme relatado no item 6.3. Estudos futuros deverão ser conduzidos para resolução de tais problemas, e em caso de não resolução da problemática, o grupo volta para a etapa de concepção de novas ideias para seguir adiante com o projeto.

O robô proposto conseguiu agregar várias características úteis à sua finalidade de busca e resgate em escombros. O formato cilíndrico, com similaridades ao formato das cobras, auxilia na locomoção em lugares de difícil acesso humano. A maior superfície de contato com o solo durante o movimento, em relação a módulos anteriores apresentados neste artigo, assim como a capacidade de incluir texturas na carcaça, permitem controlar para que o atrito seja diferente em duas direções e assim facilitar alguns movimentos específicos que dependem de atrito anisotrópico.

\section{Referências}

BENYUS, J. M. Biomimética: inovação inspirada pela natureza. 303 pp. Editora Cultrix, 2007.

DOWLING, K. J. Limbless Locomotion: Learning to Crawl with a Snake Robot. Carnegie Mellon University, 1997.

EROĞLU, A. K.; ERDEN, Z; ERDEN, A. Biological System Analysis in Bioinspired Conceptual Design (BICD) for Bioinspired Robots. Journal of Control Engineering and Applied Informatics, v. 13, n.2, pp. 81-86. SRAIT - Romanian Society of Control Engineering and Technical Informatics, 2011

GONZÁLEZ GÓMEZ, J. Modular robotics and locomotion: application to limbless robots. PhD thesis, Universidad Autónoma de Madrid, 2008.

GRAY, J. The mechanism of locomotion in snakes. Journal of Experimental Biology, v. 23 n. 2, pp. 101-120. The Company of Biologists, 1946.

GRAY, J.; LISSMANN, H. W. The Kinetics of locomotion of the Grass-Snake. Journal of Experimental Biology, v. 26, n.4, pp. 354-367. The Company of Biologists, 1950.

HIROSE S. Biologically inspired robots: snake-like locomotors and manipulators, Oxford University Press, Oxford, 1993.

HOPKINS, J. K.; SPRANKLIN, B. W.; GUPTA, S. K. A survey of snake-inspired robot designs. Bioinspiration \& Biomimetics, v. 4, n. 2. IOP Publishing, 2009.

JAYME, R. F. Influência do atrito na locomoção de robôs apodais. 2016. 62p. Dissertação - 
Universidade de Brasília. Brasília, 2016.

MATTISON, C. The encyclopedia of snakes. London: Cassell Paperbacks, 2002.

PARKER, H.GRANDISON, A. Snakes, a natural history. Ithaca, N.Y.: Cornell University Press, 1977.

PAPANEK, V. Design for the real world. 2a edição. Thames \& Hudson, Londres, 1984.

SAITO, M.; FUKAYA, M., IWASAKI, T. Modeling, analysis, and synthesis of serpentine locomotion with a multilink robotic snake. 2011 2nd International Conference on Control, Instrumentation and Automation (ICCIA 2011). IEEE, 2012.

TRANSETH, A.A.; PETTERSEN, K. Y.; LILJEBÄCK, P. A survey on snake robot modeling and locomotion. Robotica, v. 27, n. 7, pp 999-1015, Cambridge University Press, 2009.

YIM, M.; SHEN, W.M.; SALEMI, B. ET AL. Modular Self-Reconfigurable Robot Systems. IEEE Robotics \& Automation Magazine v.14, n.1, pp. 43-52. IEEE, 2007.

ZHANG, S.; GUO, Y. Bio-inspired locomotion for a modular snake robot. in Proceedings of SPIE The International Society for Optical Engineering, 7321; 73210E-2; Bio inspired - Biomimetic sensor technologies and applications. SPIE, Bellingham, Washington; 2009.

FORCELLINI, F. A. Apostila de Projeto de Produto. [S.I.]: [s.n.], 2002.

JAYNE; BRUCE C. Muscular mechanisms of snake locomotion: an electromyographic study of sidewinding and concertina modes of Crotalus cerastes, Nerodia fasciata, and Elaphe Obsoleta. Journal of Experimental Biology 140, 1-33, 1998.

JAYNE; BRUCE C.; BENNETT A.F. Tail morphology and snake locomotion. Journal of Experimental Zoology 252:126-133, 1989

SNEEL - gabriella levine. Disponível em: . Acesso em: 8 jun. 2016 